Currículo sem Fronteiras, v. 19, n. 3, p. 944-962, set./dez. 2019

\title{
A EVOLUÇÃO DA “DIVERSIDADE SEXUAL” NO CURRÍCULO ESCOLAR PORTUGUÊS: da revolução dos cravos ao neoconservadorismo
}

\author{
Hugo Santos \\ Universidade do Porto - UP
}

\begin{abstract}
Resumo
Com a emergência do neoconservadorismo a nível global, género e sexualidade estão hoje sobre ataque. As políticas públicas de educação e o currículo são o centro nevrálgico dessa luta e o contexto português não é exceção. Tem-se assistido, na esfera pública, por exemplo, à emergência de retóricas antigenderistas que procuram questionar os avanços LGBTI na sociedade. Contribuindo para o debate sobre os impactos do neoconservadorismo no currículo, e através de uma análise das alterações legislativas relevantes e do diálogo teórico estabelecido com autores/as de referência, este artigo explora a evolução da diversidade sexual no currículo escolar português, explicitando as condições que permitiram a sua emergência e discutindo os desafios colocados hoje pelos ataques reacionários aos direitos LGBTI no currículo. Espera-se, com este artigo, contribuir para tornar mais claro os desafios que se enfrentam num contexto particular.
\end{abstract}

Palavras-chave: género; sexualidade; diversidade sexual; currículo; Portugal

\begin{abstract}
With the emergence of neoconservatism globally, gender and sexuality are now under attack. Public education policies and the curriculum are the nerve center of this struggle and the Portuguese context is no exception. In the public sphere, for example, there has been an emergence of anti-liberal rhetoric seeking to question LGBTI advances in society. Contributing to the debate about the impacts of neoconservatism on the curriculum, and through an analysis of the relevant legislative changes and the theoretical dialogue established with reference authors, this article explores the evolution of sexual diversity in the Portuguese school curriculum, explaining the conditions that allowed for its emergence and by discussing the challenges posed today by the reactionary attacks on LGBTI rights in the curriculum. It is hoped that this article will help to clarify the challenges facing a particular context.
\end{abstract}

Keywords: gender; sexuality; sexual diversity; curriculum; Portugal.

ISSN 1645-1384 (online) www.curriculosemfronteiras.org 


\section{Introdução}

Em final de 2018, um conjunto de cartazes "misteriosos" apareceram junto a 300 escolas em todo território de Portugal, distribuídos em pontos estratégicos, junto a estabelecimentos educativos ou pontos de passagem de grandes massas de pessoas, como paradas de autocarro. Com uma imagética obscura, no centro dos cartazes, podia ler-se a expressão "ideologia de género”, lardeada por um símbolo de perigosidade associada a material radiativo. Quem os assinava era um grupo de pessoas anónimas intitulado, curiosamente, de "Escudo Identitário", que, alguns media portugueses, como, por exemplo, o Público, apontam como sendo um grupo de extrema-direita ${ }^{1}$. Ora, aquilo que se pensava impensável, para um dos únicos países europeus sem a representação parlamentar da extrema-direita - e também um dos únicos governado por uma legislatura de esquerda até ao fim -, acabou mesmo por acontecer: o ataque antigenderista à abordagem curricular da diversidade sexual nas escolas. Como se chegou até aqui? É a pergunta que se pode fazer.

Uma das tendências mais recentes da pesquisa educacional sobre o que se convencionalizou chamar de "género" e "sexualidade", tem passado por re-situar e interseccionalizar os debates sobre a (não-)integração dos temas, inerentemente diversos e multidimensionais, da "igualdade de género" e dos direitos de pessoas gays, lésbicas, bissexual, transgénero e intersexo (LGBTI), no currículo escolar, com os novos desafios lançados às democracias, decorrentes do crescimento e afirmação global do (neo)conservadorismo no mundo (o que inclui o populismo, o conservadorismo religioso e a extrema-direita); analisar criticamente os seus impactos e efeitos nas conquistas e avanços realizados (e por realizar), e elaborar possíveis estratégias de enfrentamento necessárias para a restituição da ordem democrática, particularmente na parte ocidental do mundo. Pode-se perceber essa tendência, por exemplo, a partir de toda uma literatura contemporânea recente sobre "pânico moral/sexual" (Cardoso, 2018; Miskolci, 2007; Rubin, 2011) ou "ideologia de género" (Corredor, 2019; Junqueira, 2018; Miskolci e Campana, 2017), com os trabalhos dos países da América Latina a assumirem a dianteira da reflexão, problematização e debate, uma vez que, compreensivelmente, são também neles onde novas formas de retórica reacionária se tornam mais visíveis (Santos, Silva, Macedo e Menezes, 2019).

Como consequência, carece-se de perspetivas oriundas de outros contextos que nos ajudem a ir mais além dos debates nacionais e sejam capazes de nos fazer refletir de modo crítico e vigilante, gerar novas formas de solidariedade transnacional e nos faça resistir proativamente aos seus efeitos mais perniciosos (Lopes, Lopes, Leite, Macedo e Tura, 2008; Santos, Silva, Macedo e Menezes, 2019). Em Portugal, decorrente das circunstâncias sociopolíticas, tem sida parca a reflexão sobre o impacto social do (neo)conservadorismo, sobretudo na educação e currículo, assim como tem sido pouca a reflexão no geral, na teoria educacional, quando o assunto é género e sexualidade (Santos, Silva e Menezes, 2017; Santos, Silva e Menezes, 2018; Santos, 2018). Apesar das conquistas legais das últimas três décadas, que colocam Portugal no $7^{\circ}$ melhor país do mundo em termos de reconhecimento legal dos direitos de pessoas LGBTI, segundos dados da ILGA Europe (https://www.ilgaeurope.org/rainboweurope/2019), pouca discussão tem havido sobre a interseção da 
diversidade sexual com o currículo escolar. A literatura que existe (cf. Carneiro e Menezes, 2007; Cascais, 2004; Cascais, 2006; Rodrigues, 2016; Santos, 2013; Santos, 2018; Silva, 2006; Vale de Almeida, 2010) tende a centrar-se mais nos aspetos dos direitos LGBTI a um nível geral do que nos efeitos e papel da educação e do currículo escolar em particular.

Partindo do argumento de Bernard Charlot (2006) que é a partir do mapeamento das ausências que os estudos em educação avançam, este artigo procura expandir o debate sobre a diversidade sexual no currículo escolar português, começando por i) traçar as condições e processos de emergência que possibilitaram a integração dos tópicos da orientação sexual e identidade de género no currículo e, posteriormente, ii) conhecer os desafios recentes à implementação das leis lançados pelo neoconservadorismo. Como fundamentação, invocase trabalhos teóricos de referência que, de modo similar, tem procurado fazer o ponto da situação dos direitos LGBTI em Portugal, e enfatiza-se o papel que os movimentos LGBTI tiveram nesse processo de integração e vai-se descrevendo as mudanças sociais factuais patentes em documentos relevantes - como decretos-leis e despachos - que refletem as mudanças sociais, sem esquecer a articulação dialógica com outros contextos (como, por exemplo, o contexto brasileiro) e os desafios que em cada período são lançados ao currículo e à educação. Como um entendimento de "como se chegou até aqui" necessita de uma imersão holística no passado, divide-se essa integração em três momentos cronológicos, correspondentes a cada uma das décadas 1990-2000, 2000-2010 e 2010-2020, e em cada momento discute-se as circunstâncias históricas que estiveram na origem do debate educacional sobre direitos LGBTI².

\section{Da "revolução dos cravos"3 às promessas de democracia íntima e sexual: os primórdios do movimento LGBTI}

Para compreender a introdução daquilo que se pode designar como "diversidade sexual”4 no currículo escolar é preciso começar por entender as políticas curriculares como sendo atravessadas por diferentes relações e formas de poder. Nesse sentido, o currículo não se limita a ser uma representação de conteúdos, materiais e práticas pedagógicas neutros ou assépticos, mas é antes uma arena na qual diferentes grupos e ideologias se digladiam na obtenção do conhecimento e discurso hegemónico ou, pelo menos, mais válido (Martins de Oliveira e Souza de Oliveira, 2018). Nesta linha crítica, para a qual os contributos de autores como Michael Apple (1997) ou Paulo Freire (2014) foram e são centrais, o conhecimento oficial do currículo resulta de uma política de acordos e alianças que se processam entre diversos atores e grupos sociais. Como tal, um trabalho pedagógico crítico implicaria um compromisso com movimentos sociais e grupos que continuamente desafiam as relações de exploração e dominação. Parte-se, pois, de uma concepção de currículo que transcende uma noção monolítica de objeto coisificado, e o considere no atravessamento entre múltiplas relações antagónicas de (não-)poder-(não-)saber (Leite, 2006; Lopes, Lopes, Leite, Macedo, 2006; Macedo e Tura, 2008; Lopes, 2012), defendendo-se que é virtualmente impossível pensar o currículo fora da esfera enredada dessas tensões (Ranniery, 2017). 
Isto é particularmente relevante no campo da sexualidade que, parecendo «estar fora» das políticas públicas de educação, «está dentro», através da sua própria ausência dissimulada. Como recordam Anna Luiza Araújo Ramos Martins de Oliveira e Gustavo Gilson Sousa de Oliveira (2018), "[a] tentativa de normatização da sexualidade sempre esteve presente nas políticas de educação desde os primórdios da modernidade” (p. 18). Até à década de 70, os valores dos/as portugueses/as relativos à sexualidade era o que, segundo os padrões atuais, se poderia designar como "conservadores". Sob a forte e histórica influência da Igreja Católica e da sua tradição judaico-cristã, a moral dominante confinava a sexualidade legítima ao modelo normativo da heterossexualidade monogâmica, enfatizava-se valores como a castidade, decoro e discrição, e pressupunha-se (pelo menos, teoricamente) que a relação sexual tivesse como fim exclusivo e último a reprodução (Carneiro e Menezes, 2007; Rocha e Duarte, 2015). Esses valores não só eram discursivamente exaltados pela ditadura salazarista do Estado Novo, que tinha como fonte ideológica de inspiração o catolicismo (Almeida, 2010), como impostos à sociedade a partir de mecanismos jurídico-legais explícitos, e quem não os cumprisse (e.g., pessoas que se relacionavam afetiva e/ou sexualmente com outras do seu próprio sexo), ficaria sujeito/a às respetivas sanções, o que, em certos casos, implicava mesmo internamento, aprisionamento e tortura (cf. Correia, 2017).

Desse modo, se falar sobre sexualidade na esfera pública era extremamente difícil, debater aspetos sobre (homo)sexualidade(s) na escola estava para lá daquilo que poderia ser imaginável. Socialmente, o(s) movimento(s) de liberação sexual, com início nos movimentos contraculturais estadunidenses, e que deram origem, ou pelo menos influenciaram, os primeiros movimentos feministas e LGBTI em outras partes do mundo, não tiveram, como explica Miguel Vale de Almeida, o mesmo tipo de impacto em Portugal por um conjunto de razões, entre as quais a

[...] a experiência da ditadura até 1974. Em segundo lugar, as transformações políticas subsequentes ao 25 de Abril privilegiaram visões do mundo de uma certa tradição da esquerda que via na homossexualidade um assunto problemático e secundário, quando não mesmo perigoso. Em terceiro lugar, o processo de "normalização" pós-revolucionário não renovou as elites, tendo conduzido ao poder ou os herdeiros daquele pensamento de esquerda ou os herdeiros do pensamento de direita avesso ao questionamento dos ordenamentos de género e sexuais. (Vale de Almeida, 2010: p. 47).

Estas circunstâncias talvez expliquem porque é que a existência de um movimento "gay" visível, eficaz e consolidado em Portugal, ao contrário de outros países industrializados, só tenha ocorrido na década de 90 e também com as suas particularidades, entre as quais o facto de ter sido os efeitos da epidemia do HIV-sida a impulsioná-lo (com os/as pacientes a reivindicarem tratamento e aceitação), em vez de derivar de uma agenda própria centrada no combate à discriminação e afirmação das identificações sexuais. A epidemia, como explica Cascais (2006), contribui ainda para que a agenda desse movimento embrionário integrasse 
uma estratégia de luta que enfatizasse "os direitos respeitantes à relação (direitos ao consentimento, à livre escolha, ao reconhecimento institucional da relação, como a união de facto e o casamento (...)” (2006: 120), o que vai marcar as reivindicações inaugurais do movimento LGBTI português em torno do reconhecimento das relações afetivas e do casamento civil.

A emergência do HIV-sida e as preocupações subsequentes com a saúde pública vão tornar imperativa a necessidade de transmissão de informação (credenciada) sobre métodos contracetivos e inaugurar os debates políticos e sociais sobre a educação sexual (ES) nas escolas (Allen, 2011; Jones, 2011; Rocha e Duarte; 2015; Santos, Silva e Menezes, 2018). Ainda que se tenha registo a introdução de temas relacionados com a sexualidade nos currículos escolares desde da década de 20, num contexto da aplicação de medidas higienistas e profiláticas (cf. Amaral, 2016), é a partir da década 80 que os debates sobre a implementação de ES se vão intensificar consubstancialmente nas sociedades ocidentais, despertado o interesses de organizações internacionais como a Federação Internacional de Planeamento Familiar (FIPF), a Organização Mundial de Saúde (OMS) e a Organização das Nações Unidas para a Educação, a Ciência e a Cultura (UNESCO), não sendo Portugal exceção (Rocha e Duarte, 2015).

Do ponto de vista educativo, a 14 de outubro de 1986 é criada a Lei de Bases do Sistema Educativo. Mais tarde dá-se a Reforma Curricular de 1989, e inicia-se um profundo processo de democratização da educação, que implicava reconhecer que na escola não se ensinava apenas os conteúdos programáticos do Português e da Matemática (Menezes, 2007). Gradualmente, a "sexualidade” passa a constar no currículo como um dos muitos tópicos a ser abordado na escola, quer em diferentes espaços - como, por exemplo, no domínio da “Formação Pessoal e Social”, quer em diversos programas de educação em saúde, ainda que sem uma legislação robusta que defina os parâmetros ou diretrizes de como ela deva ocorrer. A primeira lei a regular a ES passa no Parlamento em 1984 (Lei no. 3/84), em parte devido às ações da Associação para o Planeamento da Família (APF), mas, além de bastante superficial, não continha nenhuma referência a questões de orientação sexual ou identidade de género.

Somente nos finais da década de 90 é que se assiste à promulgação de uma lei que reforça a necessidade da ES nas escolas (Lei $n^{\circ}$. 120/99-18), e em 2000, diretrizes técnicas foram publicadas com a aprovação geral. Mas como explicam Rocha e Duarte (2015), em 2003 o novo governo conservador - Partido Social Democrata (PSD), coligado com o Centro Democrático Social - Partido Popular (CDS-PP, ou simplesmente, CDS) - cancelou o programa para “Promoção da Saúde e Educação”. Á semelhança de outros países europeus (cf. Allen, 2011), a abordagem curricular da sexualidade na escola conhecia um caminho sinuoso e errático e a sua implementação definitiva sempre foi adiada. Também nas reivindicações mais gerais em torno da orientação sexual e identidade de género, "houve um período de 19 anos em que nada sucedeu em termos de direitos LGBTQ” (Santos, 2018: p. 41), parecendo estar as possibilidades de mudança numa fase de interregno.

A nível académico, e particularmente no campo da educação, começavam a aparecer nesta década em Portugal, os primeiros trabalhos sobre identidade, diferença, diversidade, 
multiculturalismo e interculturalidade, problematizando-se sobre inclusão, democracia, justiça social, entre outros (Leite, 2002). Contudo, a produção em Portugal sobre diversidade sexual, sobretudo no campo do currículo, era, tal como hoje (Santos, 2018), ainda incipiente, para não dizer nula, significando isto que a literatura disponível para consulta era, sobretudo, de cariz internacional ${ }^{5}$. Destaca-se aqui o Brasil, onde começavam a aparecer os trabalhos seminais e pioneiros de Guacira Lopes Louro (1999; 2000; 2004) no campo do currículo, e que, diretamente ou indiretamente, dado a proximidade linguística, tamanho geográfico e maior quantidade de recursos, acaba por influenciar culturalmente Portugal, e o resto do mundo lusófono (Santos, Silva, Macedo e Menezes, 2019). O que em 1996 Debora Britzman refere sobre os anos 90 da pesquisa educacional - "estranhamente mudos sobre as polimórficas práticas sexuais da juventude (1996: p. 73) - também se aplica a Portugal, onde se regista um certo déficit, de preocupações sobre a diversidade sexual no currículo.

\section{Do armário para as ruas: construção ilusória de uma narrativa liberal e ascendente de progresso e sucesso}

A partir do final da década de 90 e durante toda a década de 2000, vão-se assistir em Portugal a um conjunto de transformações profundas que vão alterar definitivamente as atitudes, valores e posicionamentos de muitos/as portugueses face aos modos de experimentar e compreender género e sexualidade. Essas transformações envolvem, sobretudo, a politização crescente e consequente debate social sobre dois grandes temas relativos aos "costumes”: a descriminalização da interrupção voluntária da gravidez (i.e., aborto), que viria a ser legalizada em 2007 - em 1998, tinha sido realizado um referendo popular em que o "não” ganhou, mas a participação foi baixíssima (Rocha e Duarte, 2015) e o casamento entre pessoas do sexo, que, entretanto, se tornara uma demanda de nuclear importância nas agendas LGBTI europeias (Carneiro e Menezes, 2007). Neste período, em Portugal, vai-se assistir a alterações legais estruturadoras, uma consequente maior discussão pública sobre género, sexualidade e direitos LGBTI, amparada por uma incrível visibilidade mediática (Santos, 2013; Santos, 2018; Vale de Almeida, 2010).

Como recorda Ana Cristina Santos (2018), 1995 é o ano de entrada da chamada questão homossexual na esfera político-partidária portuguesa. Um facto que merece destaque é a criação das primeiras organizações LGBTI em Portugal a partir de meados da década que agora conhecem possibilidades de afirmação num contexto democrático, entre as quais, o Grupo de Trabalho Homossexual (1991), Clube Safo (1996), Opus Gay (1997), não te prives (2002). Estas organizações, de naturezas distintas, vão ter um papel importantíssimo na visibilização dos dilemas e problemáticas de pessoas LGBTI, chamando a atenção para a(s) sua(s) realidade(s), vulnerabilidade psicossocial e elaborando propostas para a sua transformação. Uma das que mais se destaca, pelo seu papel ativo e definitório daquilo que se pode chamar uma “agenda LGBTI”, é a Associação ILGA-Portugal. Iniciada pelas mãos de ativistas contra o HIV-sida no início da década de 90, a sua fundação e institucionalização dá-se em 1996, tendo direito a um espaço camarário e, mais tarde, um Centro. 
Entre as atividades pioneiras mais significativas voltadas para a comunidade destaca-se a realização do Arraial Pride e da Marcha do Orgulho, com início em 2000 e que, gradualmente, se tornarão vetores de visibilidade LGBTI no país. Além de promover um conjunto de atividades de convivência e apoio a pessoas LGBTI, e trabalhando na formação e sensibilização de profissionais de vários setores, através de alguns dos seus projetos, a Associação vai constituir uma agenda pública de reivindicações centrada na igualdade de direitos perante a lei (Carneiro e Menezes, 2007; Colling, 2015; Silva, 2006; Santos, 2013; Santos, 2018; Vale de Almeida, 2010).

Uma das suas primeiras reivindicações, por sinal pioneira, foi a inclusão da "orientação sexual” (e da “identidade de género”, que acabará por não constar) na Constituição da República Portuguesa como um dos critérios segundo os quais ninguém podia ser beneficiado/a ou prejudicado/a. Esta proposta vai-se revelar fundamentalmente inteligente uma vez que, através desse princípio da igualdade, a ação política se centrará na eliminação ou reformulação de todas as leis discriminatórias contra pessoas LGB, dos diferentes Códigos e alíneas, incluindo o acesso ao casamento civil. Assente numa via dialógica institucional, a ILGA destacar-se-á pelas suas estratégias mais moderadas e establishment de aproximação ao poder político - e, por isso, geralmente tidas como assimilacionistas, integracionistas e normalizadoras (Colling, 2015), procurando a integração nas estruturas de poder que já existem no país. Uma das estratégias utilizadas pela ILGA é o "lobbying”. Como explica Santos,

[...] lobbying visa gerar mudança através de reuniões com os tomadores de decisão, particularmente os deputados e membros do Conselho de Ministros. É empoderador na medida em que permite que os movimentos sociais assumam a liderança, exijam reuniões, coloquem informações para apresentar aos políticos. O lobby também envolve a disposição de ir além do Parlamento, se necessário, por meio de alianças que muitas vezes podem ajudar a mudar medidas e políticas." (2013; p. 151-152)

Associada à ILGA, merece destaque a criação da associação rede ex aequo, em 2004, mais voltada para jovens LGBTI (16-30 anos) e que vai ser pioneira por criar os primeiros projetos voltados para a compreensão LGBTfóbica da realidade educativa no país, uma vez que o Estado se demite desse papel (Santos, 2013). Essa compreensão acontece por via dos Observatórios de Educação - relatórios trianuais que apresentam as denúncias de discriminação e violência na escola -, e os Projeto Educação que consistem em intervenção socioeducativa em escolas procurando-se compreender conceitos, debater direitos e promover consciência. Alguns indivíduos e grupos políticos, com representação parlamentar (mais à esquerda), começam a demonstrar interesse e sensibilidade em relação a questões LGBT, e uma das primeiras iniciativas a ser discutidas pelo poder político será as uniões civis em 2001 (Carneiro e Menezes, 2007).

Também a adesão à União Europeia (EU) e a influência cultural e desenvolvimento socioeconómico que daí derivou, obrigou a uma mudança gradual de mentalidades (Carneiro 
e Menezes, 2007; Colling, 2015; Vale de Almeida, 2010), que foi sendo semeada durante toda a década de 90, desde logo pela necessidade de Portugal dar uma "boa imagem” à EU como estado-membro (Santos, 2013). As diretivas da União revelam preocupações na salvaguarda dos "direitos de homossexuais" e exercerão um papel fundamental para a mudança de mentalidades.

Todavia, apesar destas evoluções legislativas, um dos eventos que mais mobilizou os interesses políticos e despertou a consciência social foi a brutal morte da transexual brasileira Gisberta Salce Júnior, no Porto, em 2006, , um crime que chocou a sociedade portuguesa. Em toda a sua paradoxal crueldade, esse acontecimento, amplamente mediatizado, além de chamar a atenção para a problemáticas específicas das pessoas trans, nomeadamente a transfobia (Santos, 2013), teve, paradoxalmente, como efeito indireto, colocar os direitos LGBTI nas agendas políticas, e muito particularmente diferentes propostas sobre "o casamento entre pessoas do mesmo sexo" que, entretanto, se tinha tornado um tema forte noutros países europeus (Carneiro e Menezes, 2007; Santos, 2013; Santos, 2018; Vale de Almeida, 2010). A discussão sobre o casamento, entretanto legalizado em 2010, dividiu a sociedade portuguesa, mas abriu um procedente para a ampla cobertura mediática dos direitos LGBTI em Portugal, de uma forma nunca vista no país (Santos, 2013).

Estes eventos, em conjugação com uma mudança de governo (com o Partido Socialista [PS] a tomar pose em 2005), refletir-se-ão também numa retoma das discussões em torno da educação sexual. Nessa esteira, o governo decidiu convocar uma equipa de especialistas para apresentar uma proposta de implementação da ES (2005-2007), com o apoio de ambos os Ministérios da Educação e da Saúde, e o resultado deu origem à Lei n. ${ }^{\circ}$ 60/2009 que oficializa e torna obrigatória a ES nas escolas em todo o território nacional, detalhando os modos como ela deve ser implementada. Construída num modelo compreensivo, e com uma abordagem holística, transdisciplinar e participativa, a lei da ES é um marco histórico pois o seu regime de aplicação em meio escolar consagra como uma das finalidades, no seu artigo $2^{\circ}$, a eliminação de comportamentos baseados na discriminação sexual ou na violência em função do sexo ou orientação sexual, contribuindo para a sensibilização entre os jovens para a discriminação em função destes fatores. Em duas das suas finalidades pode ler-se (passa-se a citar):

“f) O respeito pela diferença entre as pessoas e pelas diferentes orientações sexuais; (...) "I) A eliminação de comportamentos baseados na discriminação sexual ou na violência em função do sexo ou orientação sexual.” (Decreto-Lei n. ${ }^{\circ}$ 60/2009).

Mais tarde, é também criado o Estatuto do Aluno e Ética Escolar (Lei nº 51/2012 de 5 de Setembro) que estabelece no $\mathrm{n}^{\circ} 1$ do artigo $7^{\circ}$ (Direitos do Aluno) e na alínea d) do artigo $10^{\circ}$ (Deveres do Aluno) o direito de ser tratado e o dever de tratar com respeito e correção qualquer membro da comunidade educativa, não podendo, em caso algum, verificar-se discriminação em razão de um conjunto de caraterísticas, entre as quais, a orientação sexual e a identidade de género. Estas duas leis, cuja influência dos movimentos LGBTI foi decisiva 
para a sua elaboração, são pioneiras pois dizem muito claramente que as questões da diversidade sexual podem e devem ser trabalhadas na escola, estando o Estado comprometido, pelo menos, teoricamente, na luta contra a discriminação homofóbica e transfóbica.

Nesta década, os direitos LGBTI, sob o tropo do casamento, vão passar a reunir também um maior interesse de organizações governamentais e não governamentais inter e transnacionais (como o Conselho da Europa, a OMS, a UNESCO), e a educação passa a ser um domínio de destaque nas recomendações para a elaboração de políticas públicas (Junqueira, 2009; Vale de Almeida, 2010). Vai-se instalando um "espaço discursivo oficial” (Martins de Oliveira e Souza de Oliveira, 2018) que é sustentado na defesa de cidadania e direitos humanos e sexuais e, ao mesmo tempo, é também quando se assiste ao aparecimento de trabalhos académicos, publicações e comunicações sobre direitos LGBT de forma crescente (Jones, 2011).

Essas transformações acabam por consolidar a ideia de que as demandas LGBTI estão posicionadas no "lado certo da história", instalando-se a ideia de uma narrativa linear de progresso e sucesso, caraterizada pela sua imbatibilidade. Dentro deste paradigma positivista e liberal, o próprio currículo escolar é percecionado como a ferramenta-chave para desbloquear o potencial individual de cada um/a e criar uma sociedade mais justa, onde as predominantes construções pedagógicas da infância e adolescência se situam nos "tornares", entendidos como algo no futuro e para o futuro da sociedade como um todo (Cardoso, 2018).

Há, porém, várias críticas a esta narrativa a três diferentes níveis: ao nível temporal (passado/presente), constrói-se a ideia positivista da inevitabilidade do sucesso, como se os avanços ou conquistas fossem, desde logo, garantidos, e não pudessem sofrer recuos e retrocessos. Como consequência, além da falaciosa binarização ética entre "passado" (necessariamente mau) e "futuro" (automaticamente bom), o presente assume uma função de passagem que acaba por não merecer a atenção das problematizações sociais. Ao nível global (ocidente vs. oriente), a narrativa linear de progresso é contada a partir de uma história ocidental e americo-euro-cêntrica que não só oblitera especificidades locais e diferenças cruciais entre movimentos e leis, como toma as dores dos ocidentais (ou ausência delas) como a regra universal (Nogueira e Oliveira, 2010). Por exemplo, nas suas reflexões inspiradas na teoria queer, Puar (2007) usa o conceito de homonacionalismo para explicar, em parte, como a gradual apresentação de "barómetros de direitos LGBTI" acaba por produzir ideias estereotipadas sobre os países "em desenvolvimento".

Ao nível local (lei/cultura), parte-se do pressuposto que as sociedades mudam por decreto, bastando modificar as leis para a sociedade alterar concomitantemente as suas atitudes, comportamentos e entendimentos normativos. Ainda que as leis nãodiscriminatórias sirvam como dispositivos essenciais para a ampliação de liberdades, é preciso haver um trabalho próximo de pedagogia social, para mudar mentalidades cujos valores homofóbicos e transfóbicos que estão culturalmente enraizados. Por exemplo, Slavoj Žižek (2018) tem discutido se a discrepância entre as leis e as práticas, sem um trabalho e debate social de fundo e profundo, não são um fundamento para a (re)emergência de posições conservadoras. Žižek nota que a recente retórica do “politicamente correto” não é mais do 
que uma reação intempestiva de quem ainda não interiorizou uma perspetiva realmente inclusiva sobre «o Outro».

\section{O início das tentativas de controlo neoconservador e a ideologia antigenderista: país de «brandos costumes»?}

Colmatar a discrepância entre a lei e as práticas torna a educação na escola definitivamente, um setor vital para a mudança social. Simultaneamente, reúne também a forte oposição de setores anti-LGBTI pelos mesmos motivos. A possibilidade de acesso ao casamento civil entre pessoas do mesmo sexo (entretanto, aprovado em 2010) foi uma questão que, pelo debate político e discussão pública que gerou, demonstrou conter uma alta densidade moral catalisadora que tanto contribuiu para expor a solidariedade de muitas pessoas, grupos, coletivos e alianças, como, simultaneamente, tornou (mais) visível os preconceitos homofóbicos daqueles/as que se opunham aos direitos de pessoas LGBTI (incluindo o direito à vida) e, por extensão, à igualdade como um valor (Santos, 2018). Uma das possíveis explicações para tal "pânico moral" " reside no facto de o CEPMS desafiar, pelo menos simbolicamente, as noções binárias de masculinidade e feminilidade arquetípicas, no interior de uma ordem heterosimbólica que é constituída pelos valores culturais dominantes enraizados. Como explica Richard Miskolci,

O casamento gay se tornou uma possibilidade que evoca temores com relação à sobrevivência da instituição em seu papel de mantenedor de toda uma ordem social, hierarquia entre os sexos, meio para a transmissão de propriedade e, principalmente, valores tradicionais. Assim, se a rejeição ao casamento gay reside neste pânico da mudança social, isto se dá porque nossa sociedade construiu historicamente a imagem de gays como uma ameaça ao status quo. (Miskolci, 2007: p. 104).

A controvérsia em torno do CEPMS teve como efeito aumentar a visibilidade das questões LGBTI nos media portugueses, mas também possibilitou, como contraposição, a emergência de vozes de indivíduos, grupos e ideologias contrárias à vida e direitos de pessoas LGBTI. Concorda-se, pois, com Conceição Nogueira e João Manuel Oliveira para quem “apesar da atenção crescente da comunidade científica e da luta dos diferentes movimentos pelos direitos humanos e sexuais os resultados são de duplo sentido, isto é, o tornar -se um domínio de maior discussão pública e de luta política e visibilidade científica tanto fez diminuir o preconceito, como também tem feito aumentar a discriminação mais aberta” (Nogueira e Oliveira, 2010: p. 10).

O outro lado da história é que os rostos dos adversários tornaram assim identificáveis. No espectro político-partidário, pode-se nomear, genericamente, a direita parlamentar, onde se inclui o PSD e o CDS, como os grandes opositores das propostas apresentadas pelos movimentos ao longo dos anos. Existe, naturalmente, algumas exceções de cada um dos lados 
dos espectros, de deputados/as que, fazendo uso da sua liberdade de voto, em situações que assim se aplica, votam de maneira contrária à indicação genérica do partido. Outros partidos, sem representação, mas constituídos, mostram-se manifestamente contra, como, por exemplo, o partido de extrema-direita português: o Partido Nacional Renovador (PNR). Assiste-se, neste período, à emergência de um novo partido político, aprovado pelo Tribunal Constitucional em 1 de julho de 2009, sob a designação de Portugal pro-Vida (PPV): o Partido Cidadania e Democracia Cristã (PPV/CDC) que defende manifestamente os princípios da doutrina social da Igreja.

$\mathrm{Na}$ sociedade civil, começam a surgir contramovimentos religiosos (e muito especificamente ligados à Igreja Católica) e outros, à partida, laicos como, por exemplo, a Plataforma Cidadania e Casamento, que manifestam a sua revigorada oposição aos direitos LGBTI (incluindo uma Marcha Pela Vida). Nas redes sociais, e muito particularmente no Facebook (que se popularizou em 2009), foram criados grupos anti-LGBTI assim como as caixas de comentários em notícias relacionadas com o tema se encheram (e ainda se enchem, não obstante uma moderação mais atenta) de observações de ódio (Barreto, 2018). Estava constituída os primórdios daquilo que Martins Oliveira e Souza Oliveira chama uma “tentativa de controlo conservador” (2018). Reportando-se à realidade do Brasil, diversos autores/as brasileiros/as (Junqueira, 2018; Martins de Oliveira e Sousa de Oliveira, 2018; Miskolci, 2007; Miskolci e Campana, 2017) também constatam que é a partir do momento que o Supremo Tribunal Federal equivale a união entre pessoas do mesmo sexo ao casamento heterossexual que um novo tipo de retórica neoconservadora parece emergir.

A partir de 2010, as reivindicações legais por igualdade e subsequentes conquistas não vão estagnar no CEPMS. Há que referir, por exemplo, o trabalho colaborativo das associações LGBTI com outros grupos e associações como aquelas que tem a igualdade de género como mote. Os Planos Nacionais da Igualdade, realizados Comissão pela Cidadania e Igualdade de Gênero, integra no seu conselho consultivo algumas organizações LGBTI. O Plano para o período 2014-2017 contém 5 medidas na área estratégica nomeada Orientação sexual e Identidade de gênero, entre as quais sensibilizar a população para a nãodiscriminação.

Entre 2010 e 2018, outras medidas vão sendo aprovadas e também elas vão suscitar bastante celeuma sendo aquelas que se relacionam, ora com a adoção ou coadoção conjunta de crianças, ora com as questões trans, aquelas que vão gerar um debate social mais acesso. Como explica Santos, “ideias predeterminadas acerca 'da família' e 'da criança' têm sido frequentemente veiculadas sempre que estão em causa reivindicações que implicam relacionamentos” (2018: 44) ${ }^{8}$. Daniel Cardoso (2018) explica como noções convencionais de ser criança são instrumentalizadas para se conseguir determinados objetivos políticos e ideológicos.

No plano da educação, os Observatórios de Educação da associação rede ex aequo deixavam bem claro a existência de situações de discriminação e bullying, sendo dos aspetos mais alarmantes dos relatórios a não apresentação de queixa. Ao longo desta década, o media tem contribuído pedagogicamente para visibilizar e denunciar situações de LGBTIfobia nas escolas, ou em contextos educativos. Foi assim, por exemplo, com o escândalo do Colégio 
Militar (escola pública de ensino militar superior) em 2016, em que o Diretor claramente aconselhava alunos/as homossexuais a saírem, violando gravemente o direito constitucional à educação.

Em 2013, em colaboração com a CIG, é lançada uma campanha contra o bullying homofóbico que, infelizmente, pouco eco teve nas escolas. Curiosamente, ao contrário de outras aprovações legais, a integração da “orientação sexual” na ES parece ter passado despercebida à maior parte da sociedade, e parece que aos estudos também, pois, carece-se de estudos em Portugal que investiguem os modos como as alíneas estão ou não a ser operacionalizadas nas escolas. Alguns estudos elaborados após o decreto-lei (cf. Rocha e Duarte, 2015), apesar de constatarem que a ES está a ser operacionalizada na maior parte das escolas, não deixam de tecer algumas observações problemáticas aos modos como ocorrem, entre os quais a pouca participação da comunidade, a falta de formação e tempo, assim como o enviesamento biologista. Este enviesamento tornar-se particularmente grave uma vez que, tal como acontece noutros contextos (cf. Allen, 2011), acaba não só por ter e passar uma visão biontológica, clínica e tecnicista da sexualidade, como também se limita a ter uma visão heteronormativa dos conteúdos.

Numa tese de Doutoramento (2018), com recurso metodológico a observação participante, entrevistas semiestruturadas e grupos focais com estudantes e professores/as, pode-se constatar que os tópicos da “orientação sexual” ou “identidade de género" raramente eram trabalhados e que havia uma necessidade de formação específica (cf. Santos, 2018).

A partir de 2018, começa-se a assistir um enrijecimento dos discursos mais conservadores na esfera pública sendo uma das suas caraterísticas mais marcantes o recurso e uso de um léxico próprio. Á semelhança do que acontece já noutros países (cf. Junqueira, 2018; Miskolci, 2017), vários termos passam a aparecer na circularidade dos entre os quais “ideologia de género". Ainda que pareça recente o seu uso, pode-se situar a emergência do conceito, como defendem vários/as autores/as (cf. Butler, 2004; Corredor, 2019; Junqueira, 2018; Ména-Lopez \& Aristizábal, 2018; Miskolci e Campana, 2017), já na década de 90, no contexto de contrarrespostas estrategicamente elaboradas pelos setores mais conservadores do Vaticano e da Igreja Católica, aos documentos elaborados e divulgados no âmbito da Conferência Internacional sobre População e Desenvolvimento no Cairo, Egito, em 1994, e na IV Conferência Mundial sobre a Mulher: Igualdade, Desenvolvimento e Paz, realizada em Pequim, no ano seguinte, ambas promovidas pelas Nações Unidas. A primeira pronunciação sobre aquilo que se convencionalizou chamar "ideologia de género", sem uma definição operacional, foi feita pelo papa João Paulo II (1975-20) e, posteriormente, pelo papa Benedito XVI (2005-2013), sem esquecer o papa Francisco (2013), que afirmam que a "ideologia de género”, ao negligenciar as diferenças sexuais e a complementaridade entre sexos, destrói a base antropológica da família e, por extensão, representa uma ameaça à humanidade,

Nesses documentos, de alcance global, reconhecia-se as desigualdades sistemáticas das mulheres no mundo inteiro e, como lembrança nevrálgica dessa desigualdade, proponha-se usar a categoria "género" como um substituto para "sexo", o que acabou por gerar o desagrado do Vaticano. Como lembra Judith Butler (2004: 182), o Vaticano não só insistiu que a Plataforma para a Ação se retornasse a noção linguística de "sexo”, num aparente 
esforço de assegurar o link entre a feminilidade e a maternidade como uma necessidade naturalmente e divinamente ordenada, como denunciou o termo como um código para homossexualidade (!). Nesta perspetiva alarmista, a construção de uma ideologia desse nível, ao dar a entender que estaria em causa uma endoutrinação homossexualizadora de crianças e jovens, com a ajuda de grandes grupos globais, descontextualizado e deturpando os fundamentos das Conferências, procurava-se a partir da diabolização e pânico moral, formar e mobilizar uma grande camada da população contra a igualdade de género e LGBTI.

A propagação gramatical da noção de “ideologia de gênero” teve início, sobretudo, na América Latina, e muito particularmente na Argentina e no Brasil, alastrando-se depois a outros países do continente. Como explica Junqueira (2009; 2018), o evento realmente catalisador vai ser a divulgação do material didático do programa federal "Escola sem homofobia" (2004), apelidado pelos conservadores de "kit gay”, que seria distribuído em seis mil escolas públicas, mas que, depois de forte oposição, foi vetado pela presidente Dilma Rousseff. Em Portugal, um dos gatilhos foi a proposta de Lei n. ${ }^{\circ}$ 38/2018 de 7 de agosto que reconhecia "o direito à autodeterminação da identidade de género e expressão de género e à proteção das características sexuais de cada pessoa”, também conhecida como "lei da identidade de género". Em termos fundamentais, esta lei viria a baixar a idade da mudança de género dos 18 (idade da maioridade em Portugal) para os 16 anos - significa isto que adolescentes em transição poderiam já alterar o nome próprio e a menção ao sexo no registo civil -, assim como tornava dispensável a existência de um relatório médico.

Em 2011, tinha sido criada uma proposta de procedimento de mudança de sexo e de nome próprio no registo civil, que torna dispensável processar-se o Estado para o efeito, representando um avanço para as pessoas trans. Necessita-se, porém, um relatório elaborado e subscrito por uma equipa multidisciplinar a comprovar "o diagnóstico de perturbação de identidade de género", o que acabava por ter um forte envies patologizante (cf. Rodrigues, 2016). Fruto dos apelos de setores importantes do movimento LGBTI português que tinham a despatologização trans como mote (Colling, 2015), e imbuída no espírito do seu tempo com a retirada da transexualidade como doença pela Organização Mundial da Saúde, esta proposta perdia o carater patologizante e concentrava-se na autodeterminação de género. A proposta acabou por vetada pelo presidente por este considerar que seria necessário um relatório medico, mas devolvida ao parlamento e aprovada. A visibilização mediática desta proposta conduziu a uma espécie de pânico moral sobre infância e mudança de género, quase sugerindo que se pretendia uma "transexualização em massa das crianças"9. Mais recentemente, em 2019, para reforçar a lei, especialmente na parte referente á educação, foi criado um despacho do governo ( $\mathrm{n}^{0}$ 7247/2019, de 16 agosto) que contemplava como medidas para a educação:

a) Prevenção e promoção da não discriminação;

b) Mecanismos de deteção e de intervenção sobre situações de risco;

c) Condições para uma proteção adequada da identidade de género, expressão de género e das características sexuais das crianças e dos jovens;

d) Formação dirigida a docentes e demais profissionais. 
O despacho prevê que uma criança trans (ou com outras caraterísticas específicas) possa ter uma pessoa adulta de referência na escola, com formação adequada, com quem possa comunicar e que a possa ajudar a desenhar formas de garantir a sua proteção e privacidade no acesso a casas de banho e balneários, prevenindo a sua exposição e protegendo sua singularidade. A medida será aplicada em relação a crianças e adolescentes que estejam a passar pelo processo de transição (ou se preparam para o fazer), e cujos pais ou encarregados de educação tenham dado autorização, não sendo uma decisão exclusiva do/a aluno/a. Contudo o despacho foi amplamente repudiado e deturpado, sendo confundido com o acesso a casas-de-banho. Uma petição pública com 20.000 assinaturas foi criada e conseguiu reunir mais de 20.000 assinaturas numa semana. Já anteriormente, perante esta proposta, um grupo de 86 deputados/as do PSD e do CDS tinha feito ao Tribunal Constitucional um pedido de fiscalização sucessiva da lei, argumentando que a Constituição proíbe o ensino de doutrinas ou ideologias nas escolas — e considerando que o artigo $12 .^{\circ}$ da lei representava precisamente a inclusão da referida “ideologia de género” no currículo escolar. É a primeira vez que os setores de direita moderada (PSD) utilizam a expressão "ideologia de género", deixando bem claro que está em curso um ataque à diversidade sexual no currículo.

\section{Considerações finais}

Este artigo procurou fazer uma evolução dos modos como a diversidade sexual foi surgindo nas políticas curriculares em Portugal (em especial na ES), com recurso a trabalhos teóricos e análise da legislação. Essa evolução não pode esquecer o papel que os movimentos (e contramovimentos) da sociedade civil (nomeadamente LGBTI e antiLGBTI) tiveram ao estabelecer as condições dessa emergência - ou revogação. Nesse sentido, o currículo não é impermeável aos dinamismos sociais; pelo contrário: é uma arena na qual vários grupos se defrontam na obtenção de um discurso hegemónico (Apple, 1997). O estabelecimento daquilo que é considerado o conhecimento oficial depende sempre dos resultados dessas lutas e tensões.

Como se viu, vários foram os acontecimentos que moldaram "as políticas sexuais” (Rubin, 2011) de escola, nestas três últimas décadas. Nos anos 90, os debates sobre a sexualidade na escola se iniciaram, mas o percurso curricular da ES foi profundamente errático. Decorrente de o(s) movimento(s) LGBTI ainda não estarem consolidados, menções à diversidade sexual eram nulas. Após um período de "normalização democrática" em se viveram “políticas apoiadas em estratégias top-down” (Leite, 2006: 69), nos anos 90 temos uma mudança paradigmática em que se previa o envolvimento e participação das comunidades educativas locais na identificação das caraterísticas e problemas e subsequente delineação de estratégias para a ação. Na década de 2000, é quando acontecem um conjunto de transformações culturais sobre género e sexualidade e as reivindicações sobre igualdade LGBTI se tornam mais visíveis. Com a influência da EU e de um cenário político favorável virado à esquerda, várias reivindicações foram atendidas - como o casamento civil entre 
pessoas do mesmo sexo. É neste período em que a ES se torna obrigatória nas escolas e traz consigo a referência à diversidade sexual.

Contudo, à medida que os direitos dos homossexuais se tornam mais visíveis e adquirem uma dimensão inevitavelmente política, também os seus adversários se tornam mais ativos, constituindo, inclusive, contramovimentos (Corredor, 2019), como numa espécie de "zigzag” (Foucault, 2011). Isto é particularmente relevante nas questões transgénero, das crianças e da escola (Cardoso, 2018; Santos, 2018). Durante muito tempo, se foi atordoado por uma narrativa linear de progresso e sucesso, gerando-se uma sensação psicológica de inevitabilidade de revirada, mas a intensidade dos backlashes conservadores nos demonstram exatamente o contrário: a qualquer momento direitos nos podem ser retirados. Desde do início do fim da crise, Portugal tem também enveredado por uma política de sucesso, um oásis para o progressismo de esquerda numa europa mergulhada no conservadorismo. Os últimos acontecimentos têm demonstrado que nem Portugal, com uma tradição revolucionária desde de 1974, pode escapar a uma agenda ideológica tácita de alcance global (Corredor, 2019). A educação e o currículo parecem ser simultaneamente o centro nevrálgico dos embates para aqueles que querem transformar a sociedade (para lá das leis), como para aqueles que vêm nessa mudança uma ameaça para a sua agenda separatista e desqualitária, procurando manter, a todo o custo, o status quo cultural da LGBTIfobia, da heteronormatividade e da cisnormatividade.

\section{Notas}

1. https://www.publico.pt/2018/11/09/p3/noticia/grupo-extremista-cola-cartazes-ideologia-genero-300-escolas-1850535

2. Ainda que se destaque estas décadas, reconhece que os acontecimentos não se podem circunscrever a um espaço tão limitado ou restrito de tempo. Longe de incorrer numa uma interpretação positivista e objetivante da história, apenas usa-se a noção de “décadas” para tornar o argumento do texto mais coerente e visível.

3. Trata-se de outra designação para a Revolução do 25 de abril de 1974, onde, através de um golpe militar com a vasta adesão da população, se pôs fim à ditadura do Estado Novo, vigente desde de 1933, de inspiração ultraconservadora e liderada por António Oliveira Salazar. Conta a história que, no dia 25, logo após a senha para a intervenção, uma florista (Celeste Caeiro), começou a distribuir cravos pelos soldados, colocando-os nas espingardas, num gesto de solidariedade que foi seguido pelos populares presentes. O cravo tornou-se, pois, um símbolo de uma revolução pacífica.

4. Dá-se o nome de "diversidade sexual” às questões da orientação sexual e da identidade de género.A opção pelo termo, invés de "LGBTI", é que a ideia de "diversidade” permite-nos conjugar, pelo menos do ponto de vista do discurso escrito, as questão da orientação sexual com os temas da identidade, diversidade e interculturalidade (Santos, Silva, Macedo e Menezes, 2019).

5. A problematização da homofobia na educação inicia-se na década de 90. Como refere Jones (2011), é a partir desse período que, quer organizações académicas-chave, quer pesquisadores/as, começam a publicar e formar networks sobre a pesquisa LGBTI em educação. Dada a história da própria homossexualidade, compreende-se que tenha sido a Psicologia a ciência a deter "o "monopólio da discursividade sobre homossexualidade" (Cascais, 2004: p. 29), mas também noutras ciências sociais, se vai verificando trabalhos sobre questões LGBTI. Importa realçar que é também nesta década que o "género" se constitui como um proeminente objeto de estudo, graças à maior interpelação dos olhares feministas sobre o papel da escola na reprodução das desigualdades, estudando-se, ora as raparigas/mulheres no contexto educacional da escola, ora, numa perspetiva performativa, a construção do género (estereótipos, etc.), com a constituição da masculinidade como um problema (Butler, 2017).

6. Os debates e tensões existentes entre diferentes formas de ativismo que, entretanto, emergem em outros contextos como o estadunidense ou brasileiro, também se vão refletir no ativismo português, ainda que a uma escala distinta, e torna-se 
mais evidente com a criação dos Panteras Rosa em 2004 que, numa perspetiva crítica de ativismo queer, se distancia de uma perspetiva mais liberal, comum na ILGA (e.g., recusa financiamento público), carateriza-se por uma estrutura organizativa horizontal envereda por estratégias de "ação direta” (incluindo desobediência civil) e solidariedade interseccional (nomeadamente, com coletivos anticapitalistas), e define como prioridades, por exemplo, a despatologização das identidades trans (cf. Colling, 2015).

7. Termo amplamente trabalhado por Stanley Cohen (1972) para descrever o sentimento de preocupação, medo e insegurança exagerado por em relação a um determinado fenómeno (real ou fictício), amplificado pelos media (cf. Miskolci e Campanha, 2017). Quando envolve componentes associadas à sexualidade humana, diz-se "pânico sexual” (Rubin, 2011).

8. Em causa, estava a discriminação no acesso à adoção, apadrinhamento civil e demais relações jurídicas familiares - Lei $n^{\circ}$ 2/2016 de 29 de Fevereiro alteração à Lei ${ }^{\circ}$ 7/2001, que, posteriormente, em 2016, é aprovada, no mesmo ano em que se dá o alargamento do âmbito dos/as beneficiários/as das técnicas de procriação medicamente assistida, caindo a discriminação com base na orientação sexual para casais de mulheres (Lei nº 17/2016 de 20 de Junho - alteração à Lei $\left.n^{\circ} 32 / 2006\right)$.

9. Um bom exemplo desse pânico foi a notícia sobre uma pesquisa feita numa escola do Porto em que se perguntava a orientação sexual dos alunos e que conduziu a uma revolta da população: https://ionline.sapo.pt/artigo/629366/escolapergunta-a-criancas-do-5-ano-qual-orientacao-sexual-foto?seccao=Portugal

\section{Referências bibliográficas}

ALLEN, L. Young people and sexuality education. Rethinking key debates. Basingstoke: Palgrave Macmillan, 2011.

ALMEIDA, S. J. Homossexuais no Estado Novo. Lisboa: Sextante Editora, 2010.

AMARAL, A. Da medicina escolar à saúde da escola. A medicina e a saúde escolar em Portugal (finais do século XIX, início do século XX). Tese de Doutoramento em Ciências da Educação. Faculdade de Psicologia e de Ciências da Educação da Universidade do Porto, 2016.

APPLE, MICHAEL W. Conhecimento oficial: a educação democrática numa era conservadora. Petropólis; Vozes, 1997.

BARRETO, V. A pesquisa em práticas sexuais: políticas e moralidades na academia. Revista Antropolítica, 43, 2017, p.203-229.

BRITZMAN, D. P. O que é essa coisa chamada amor: Identidade homossexual, educação e currículo. Educação e Realidade, volume 21, 71-96, 1996.

BUTLER, J. Undoing gender. New York: Routledge, 2004.

BUTLER, J. Problemas de género. Feminismos e subversão da identidade. Orfeu Negro, 2017.

CARDOSO, D. Notas sobre a criança transviada: considerações queerfeministas sobre infâncias. Periódicus, 1(9), 214-233, 2018.

CARNEIRO, N. S., \& MENEZES, I. From an oppressed citizenship to affirmative identities. Lesbian and gay political participation in Portugal. Journal of Homosexuality, volume 53, 65-82, 2007.

CASCAIS, A. F. Um nome que seja seu: dos estudos gays e lésbicos à teoria queer In: CASCAIS, A. F. Indisciplinar a Teoria: Estudos gays, Lésbicos e Queer. Lisboa: Fenda, 2004. p. 28-89.

CASCAIS, A. F. Diferentes como só nós. O associativismo GLBT português em três andamentos. Revista Crítica de Ciências Sociais, 76: 109-126, 2006.

CHARLOT, B. A pesquisa educacional entre conhecimentos, políticas e práticas: Especificidades e desafios de uma área de saber. Revista Brasileira de Educação, volume 11(31), 7-1, 2006.

COHEN, S. Folk devils and moral panics: the creation of mods and rockers. London: MacGibbon \& Kee, 1972. 
COLLING, L. Que os outros sejam o normal. Tensões entre o movimento LGBT e o ativismo queer. Salvador: EDUFBA, 2015.

CORREIA, A. C. O Estado Novo e a repressão da homossexualidade, 1933-1943. Ler História, 70, 161-181, 2017.

CORREDOR, E. S. Unpacking “gender ideology” and the global right’s antigender countermovement. Signs: Journal of Women in Culture and Society, vol. 44, no. 3, 613-648, 2019.

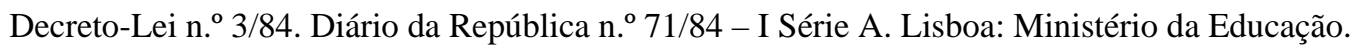

Decreto-Lei n. ${ }^{\circ}$ 120/99. Diário da República n. ${ }^{\circ}$ 186/99 - I Série A. Lisboa: Ministério da Educação.

Decreto-Lei n. ${ }^{\circ}$ 60/09 de 6 de agosto. Diário da República n. ${ }^{0}$ 151/09 - I Série A. Lisboa: Ministério da Educação.

Decreto-Lei n. ${ }^{\circ}$ 51/12 de 5 de setembro. Diário da República n. ${ }^{\circ}$ 172/12 - I Série A. Lisboa: Ministério da Educação.

FREIRE, P. A pedagogia do oprimido. Rio de Janeiro: Paz de Terra, 2014.

FOUCAULT, M. The gay science. Critical Inquiry, 37, 385-403, 2011.

GTES-Grupo de Trabalho de Educação Sexual (2005). Relatório Preliminar do Grupo de Trabalho de Educação Sexual. www.min-edu.pt

GTES-Grupo de Trabalho de Educação Sexual (2007). Educação para a saúde nas escolas: relatório final. www.min-edu.pt

JONES, T. M. How sex education research methodologies frame GLBTIQ students. Sex Education, 13:6, 687701, 2013.

JUNQUEIRA, R. D. Homofobia nas escolas: um problema de todos. In: JUNQUEIRA, R. D. Diversidade Sexual na Educação: problematizações sobre a homofobia nas escolas. Brasília: UNESCO, 2009. p. 1351.

JUNQUEIRA, R. D. A invenção da "ideologia de gênero": a emergência de um cenário político-discursivo e a elaboração de uma retórica reacionária antigênero. Psicologia Política, 18(43), 449-502, 2018.

LEITE, C. O currículo e o multiculturalismo no sistema educativo português. Lisboa: Fundação Calouste Gulbenkian, 2002.

LEITE, C. Políticas de currículo em Portugal e (im)possibilidades da escola se assumir como uma instituição curricularmente inteligente. Currículo Sem Fronteiras (BR), 6(2), 67-81, 2006.

LOPES, A. C. Democracia nas políticas de currículo. Cadernos de Pesquisa, 42(147), 700-715, 2012.

LOPES, A. C.; LEITE, C.; LOPES, A.; MACEDO, E.; TURA, M. L. Políticas educativas e dinâmicas curriculares em Portugal e no Brasil. Rio de Janeiro: Faperj, 2008.

LOURO, G. L. Gênero, sexualidade e educação: uma perspectiva pós-estruturalista. Petrópolis: Editora Vozes, 1999.

LOURO, G. L. Currículo, género e sexualidade. Porto: Porto Editora, 2000.

LOURO, G. L. Um corpo estranho: Ensaios sobre sexualidade e teoria queer. Belo Horizonte: Autêntica, 2004.

MARTINS DE OLIVEIRA, A.; SOUSA DE OLIVEIRA, G. Novas tentativas de controle moral da educação: conflitos sobre gênero e sexualidade no currículo e na formação docente. Educação Unisinos, 22(1):16-25, 2018.

MENA-LÓPEZ, M.; ARISTIZÁBAL, F. Las falacias discursivas en torno a la ideologia de género. ex æquo, 37, 19-31, 2018.

MENEZES, I. Evolução da cidadania em Portugal. In: Actas do $3^{\circ}$ Encontro de Investigação e Formação: Educação para a Cidadania e Culturas de Formação, Lisboa: ESSE, 2007. p. 17-34. 
M.E. \& M.S. Educação Sexual em Meio Escolar. Linhas Orientadoras. Lisboa: Editorial do Ministério da Educação, 2009.

MISKOLCI, R. Pânicos morais e controle social - reflexões sobre o casamento gay. Cadernos Pagu, (28), 101128, 2007.

MISKOLCI, R.; CAMPANHA, M. “Ideologia de gênero”: notas para a genealogia de um pânico moral contemporâneo. Revista Sociedade e Estado, 32(3), 725-747, 2017.

NOGUEIRA, C.; OLIVEIRA, J. M. Estudo sobre a discriminação em função da orientação sexual e da identidade de género. Lisboa: Comissão para a Igualdade de Género, 2010.

PUAR, J. Terrorist Assemblages: Homonationalism in queer times. Durham, NC: Duke University Press, 2007.

RANNIERY, T. “Sexualidade na escola”: É possível ir além da máquina de diferentes. In: MACEDO, E.; RANNIERY, T. Currículo, sexualidade e ação docente. Petrópolis: DP Et alli, 2017. p. 13-38.

ROCHA, A. C.; DUARTE, C. Sexuality education in a representative sample of portuguese schools: Examining the impact of legislation. The European Journal of Contraception and Reproductive Health Care, 20: 47-56, 2015.

RODRIGUES, L. Viagens trans(género) em Portugal e no Brasil: uma aproximação psicológica feminista crítica. Tese de Doutoramento em Psicologia: FPCE-UP: Porto, 2016.

RUBIN, G. Deviations. A Gayle Rubin Reader. Durham \& London: Duke University Press, 2011.

SANTOS, A. C. The politics of sexuality in Portugal: Confronting tradition, enacting change. In: HINES, S.; TAYLOR, Y. Sexualities: Past Reflections, Future Directions. Basingstoke: Palgrave Macmillan, 2012. p. 168-185.

SANTOS, A. C. Social movements and sexual citizenship in Southern Europe. Basingstoke: Palgrave Macmillan, 2013.

SANTOS, A. C. Luta LGBTQ em Portugal: Duas décadas de histórias, memórias e resistências. Revista TransVersos, 14, 36-51, 2018a.

SANTOS, H., SILVA, S. M.; MENEZES, I. Para uma visão complexa do bullying homofóbico: Desocultando o quotidiano da homofobia nas escolas. ex aequo, 36: 117-132, 2017.

SANTOS, H., SILVA, S. M.; MENEZES, I. From liberal acceptance to intolerance: discourses on sexual diversity in schools by portuguese young people. Journal of Social Science Education, 17(1), 55-65, 2018.

SANTOS, H. Discursos sobre bullying e homofobia na e da escola: Que (im)possibilidades de cidadania para jovens LGBT? (Tese de Doutoramento). Faculdade de Psicologia e de Ciências da Educação da Universidade do Porto, Porto, Portugal, 2018b.

SANTOS, H; SILVA, SOFIA M. S., MACEDO, E.; MENEZES, I. Diversidade sexual no discurso de professores: Os perigos liberais da híper-humanização, privatização e heteronormalização. In: MACEDO, E.; MENEZES, I. Currículo, política e cultura: Conversas entre Brasil e Portugal. Curitiba: CRV, 2019. p. 269-288.

SILVA, A. S. DA Marchando pelo Arco-Íris da Política: A Parada Orgulho LGBT na Construção da Consciência Coletiva dos Movimentos LGBT no Brasil, Espanha e Portugal. Dissertação de Doutoramento. Pontifícia Universidade Católica de São Paulo, 2006.

VALE DE ALMEIDA, M. O contexto LGBT em Portugal. In: NOGUEIRA, C.; OLIVEIRA J.M. Estudo sobre discriminação em função da orientação sexual e da identidade de género. Lisboa: Comissão para a Cidadania e Igualdade de Género, 2010. p. 45-92.

ŽIŽEK, S. Como derrotar Trump e outros ensaios. Lisboa: Relógio D’Agua Editores, 2018. 


\section{Correspondência}

Hugo Santos: É mestre e doutor em Ciências da Educação pela Faculdade de Psicologia e Ciências da Educação da Universidade do Porto (Portugal).

E-mail: hugosantos@fpce.up.pt

Texto publicado em Currículo sem Fronteiras com autorização do autor 